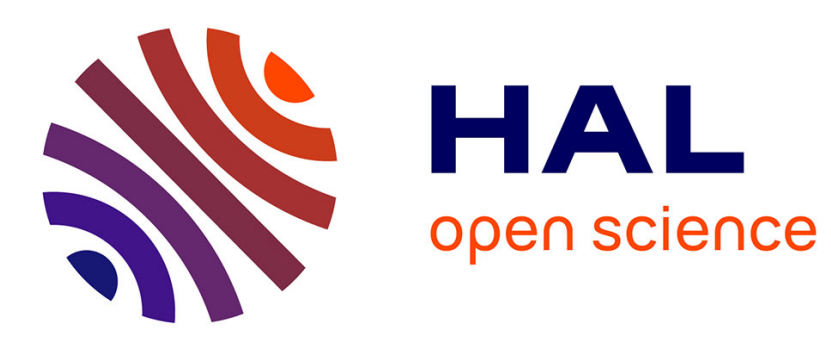

\title{
Modelling Diurnal and Intraseasonal Variability of the Ocean Mixed Layer
}

D. J. Bernie, S. J. Woolnough, J. M. Slingo, Éric Guilyardi

\section{To cite this version:}

D. J. Bernie, S. J. Woolnough, J. M. Slingo, Éric Guilyardi. Modelling Diurnal and Intraseasonal Variability of the Ocean Mixed Layer. Journal of Climate, 2005, 18, pp.1190-1202. 10.1175/JCLI3319.1 . hal-00122852

\section{HAL Id: hal-00122852 \\ https://hal.science/hal-00122852}

Submitted on 19 Feb 2021

HAL is a multi-disciplinary open access archive for the deposit and dissemination of scientific research documents, whether they are published or not. The documents may come from teaching and research institutions in France or abroad, or from public or private research centers.
L'archive ouverte pluridisciplinaire HAL, est destinée au dépôt et à la diffusion de documents scientifiques de niveau recherche, publiés ou non, émanant des établissements d'enseignement et de recherche français ou étrangers, des laboratoires publics ou privés. 


\title{
Modeling Diurnal and Intraseasonal Variability of the Ocean Mixed Layer
}

\author{
D. J. Bernie, S. J. Woolnough, And J. M. Slingo \\ Centre for Global Atmospheric Modelling, Department of Meteorology, University of Reading, Reading United Kingdom \\ E. GUILYARDI \\ Centre for Global Atmospheric Modelling, Department of Meteorology, University of Reading, Reading United Kingdom, and \\ Laboratoire des Sciences du Climat et de l'Environnement, CEA-CNRS, Gif-sur-Yvette, France
}

(Manuscript received 13 August 2003, in final form 23 August 2004)

\begin{abstract}
The intraseasonal variability of SST associated with the passage of the Madden-Julian oscillation (MJO) is well documented; yet coupled model integrations generally underpredict the magnitude of this SST variability. Observations from the Improved Meteorological Instrument (IMET) mooring in the western Pacific during the intensive observing period (IOP) of the Tropical Ocean Global Atmosphere Coupled Ocean-Atmosphere Response Experiment (TOGA COARE) showed a large diurnal signal in SST that is modulated by the passage of the MJO. In this study, observations from the IOP of the TOGA COARE and a one-dimensional (1D) ocean mixed layer model incorporating the $K$-Profile Parameterization (KPP) vertical mixing scheme have been used to investigate the rectification of the intraseasonal variability of SST by the diurnal cycle and the implied impact of the absence of a representation of this process on the modeled intraseasonal variability in coupled GCMs. Analysis of the SST observations has shown that the increase of the daily mean SST by the diurnal cycle of SST accounts for about one-third of the magnitude of intraseasonal variability of SST associated with the Madden-Julian oscillation in the western Pacific warm pool.

Experiments from the 1D model forced with fluxes at a range of temporal resolutions and with differing vertical resolution of the model have shown that to capture $90 \%$ of the diurnal variability of SST, and hence $95 \%$ of the intraseasonal variability of SST, requires a 3-h or better temporal resolution of the fluxes and a vertical grid with an upper-layer thickness of the order of $1 \mathrm{~m}$. In addition to the impact of the representation of the diurnal cycle on the intraseasonal variability of SST, the strength of the mixing across the thermocline was found to be enhanced by the proper representation of the nighttime deep mixing in the ocean, implying a possible impact of the diurnal cycle onto the mean climate of the tropical ocean.
\end{abstract}

\section{Introduction}

It is generally accepted that the interaction between the atmosphere and ocean is central to the development of the El Niño-Southern Oscillation (ENSO). It has also become increasingly apparent since the Tropical Ocean Global Atmosphere Coupled OceanAtmosphere Response Experiment (TOGA COARE) that air-sea coupling is also important over much shorter time scales than just the interannual variability of ENSO and the seasonal cycle.

Observations from the intensive observing period (IOP) of TOGA COARE (Weller and Anderson 1996) show intraseasonal variations of sea surface temperature (SST) associated with the passage of the atmo-

Corresponding author address: Mr. D. J. Bernie, Centre for Global Atmospheric Modelling, Department of Meteorology, University of Reading, P.O. Box 243, Reading RG6 6BB, United Kingdom.

E-mail: d.j.bernie@reading.ac.uk spheric Madden-Julian oscillation (MJO), which exhibit a 20-40-day period and a magnitude of $0.5^{\circ}$ to $1^{\circ} \mathrm{C}$ (Fig. 1). Studies of observations from much larger temporal and spatial domains (Hendon and Glick 1997; Shinoda et al. 1998; Woolnough et al. 2000) have shown the relationship of these SST anomalies to the different flux regimes of the active and suppressed phases of the $\mathrm{MJO}$, as well as their coherence through the Indian Ocean and western Pacific, as far as the date line. These SST anomalies are at least as large as those associated with the seasonal cycle or ENSO. In addition, Woolnough et al. (2001) have shown that these SST anomalies are capable of organizing atmospheric convection on intraseasonal time scales. The demonstrated link between the convection and SST suggests that the MJO is indeed a coupled ocean-atmosphere phenomena, as proposed by, for example, Flatau et al. (1997), or at least strongly modified by ocean-atmosphere interaction.

The potential importance of air-sea interaction for the $\mathrm{MJO}$ is also supported by its poor representation in 

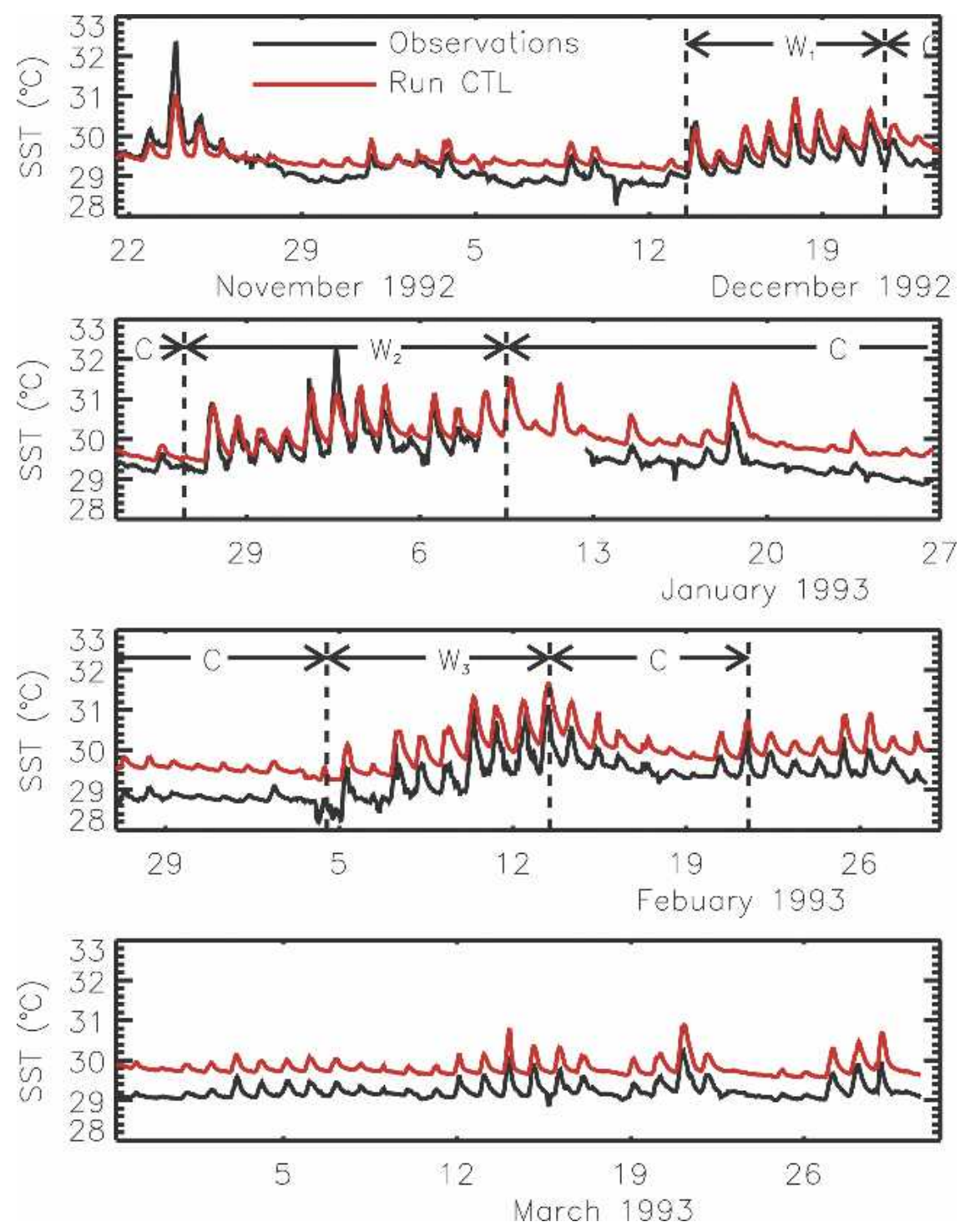

FIG. 1. Time series of SST from IMET observations (black) and control integration (run CTL) of 1D KPP model (red). Intraseasonal periods of warming and cooling are marked W and $\mathrm{C}$, respectively.

atmospheric general circulation models (AGCMs) (Slingo et al. 1996) and its improvement in AGCMs coupled to mixed layer models (Waliser et al. 1999; Shinoda and Hendon 1998) or a full ocean GCM (Inness and Slingo 2003). Although the use of coupled ocean-atmosphere models tends to improve the representation of the MJO, the results have also raised further issues. For example, Inness et al. (2003) noted that errors in the basic state of coupled models, particularly in the surface winds, could compromise the air-sea coupling and affect the eastward propagation of the MJO. Furthermore, Inness and Slingo (2003) showed that, despite realistic variations in surface fluxes associated with the MJO, the coupled model significantly underestimated the SST response. They argued that this could be due to inadequacies in the representation of the upper ocean.

As well as significant intraseasonal variability, observations from the IOP of TOGA COARE (Fig. 1) also show that, during the suppressed phase of the MJO, the western Pacific exhibits diurnal variations of SST of the order of $1^{\circ} \mathrm{C}$ and occasionally as large as $2^{\circ} \mathrm{C}$. As noted by Shinoda and Hendon (1998), these may have an impact on longer time scales, with the implication that they may be important in the mean hydrological cycle and energy balance of the warm pool.

There is also evidence that, during suppressed phases of the MJO, the diurnal cycle of tropical atmospheric convection is more typical of a continental than an oceanic regime (Johnson et al. 1999). This suggests that 
under these conditions the diurnal cycle of tropical atmospheric convection may be a direct response to the diurnal variability of SST and that feedbacks between the atmosphere and ocean can potentially operate on diurnal time scales. If this high-frequency coupling and its possible implications for the MJO are to be investigated in modeling experiments, then it is imperative that the oceanic response to diurnally varying fluxes is accurately reproduced.

Most previous studies have neglected the effect of the diurnal cycle in the upper ocean on the coupling between ocean and atmosphere (Hendon 2000). Those that have used rather crude representations of the oceanic mixed layer (Waliser et al. 1999; Wang and Xie 1998; Shinoda and Hendon 1998), which are unable to capture the diurnal variability of SST or any impact it may have on intraseasonal time scales. Additionally, such models cannot reproduce the fine vertical structure that has been observed in the western Pacific (Lukas and Lindstrom 1991) or its effects on the longer time-scale variability of the mixed layer and SST (Anderson et al. 1996; Shinoda et al. 1998).

This study examines the roles of the different vertical processes of the diurnal cycle in the upper ocean and their importance for longer time-scale evolution of the mixed layer. Recommendations are made for the vertical resolution of the upper ocean and coupling frequency necessary for coupled climate models to accurately represent the diurnal cycle in the upper ocean and its rectification of intraseasonal time-scale variability.

The investigation is performed using a high-resolution one-dimensional (1D) vertical mixing model forced with observed fluxes from the Improved Meteorological Instrument (IMET) on the Woods Hole Oceanographic Institution (WHOI) mooring in the western Pacific located at $1^{\circ} 45^{\prime} \mathrm{S}, 156^{\circ} \mathrm{E}$ (Weller and Anderson 1996). This buoy was deployed as part of the intensive flux array (IFA) of TOGA COARE with the aim of providing a significantly more accurate and complete description of the surface fluxes and subsurface temperature, salinity, and currents in this region than was previously available. Results from the IOP, from December 1992 to March 1993, have provided a dataset of very high quality with high temporal resolution surface flux and subsurface ocean measurements, which have been widely used for examination of the processes that maintain and perturb the warm pool (Anderson et al. 1996; Feng et al. 2000; Richards and Inall 2000; Shinoda and Hendon 1998; Weller and Anderson 1996).

The upper ocean of the warm pool is characterized by weak surface currents and small horizontal gradients of temperature and salinity, and, as such, the dominant variability is due to vertical processes rather than horizontal advection (Feng et al. 2000; Weller and Anderson 1996), except during rare westerly wind bursts (Cronin and McPhaden 1998; Richards et al. 1995). Together with the subsurface data for model initialization and validation, the accuracy of the surface fluxes and the dominance of subseasonal warm pool variability by $1 \mathrm{D}$ processes make the IMET IOP observations ideal for use in this $1 \mathrm{D}$ modeling study.

How the ocean responds to atmospheric fluxes of heat, freshwater, and momentum will ultimately determine the feedback to the atmosphere through the SST and hence fluxes of heat and moisture. Ocean salinity is an important feature of this response. The presence of salinity anomalies in the ocean acts to modify the evolution of mixed layer depth and thus has an important indirect effect upon the SST and ocean-atmosphere heat fluxes. However, the IMET buoy has fewer salinity sensors than temperature sensors, making it difficult to quantify the effects of salinity on the evolution of the mixed layer. In addition, the spatial heterogeneity of the precipitation field combined with the fact that advection is a significant term of the warm pool salinity budget (Dourado and Caniaux 2003; Feng et al. 2000) has meant that only the thermal evolution of the mixed layer has been addressed in this paper.

The structure of this paper will be as follows. Section 2 describes the methodology used in this paper in terms of defining and diagnosing diurnal and intraseasonal variability as well as the configuration of the model. Section 3 presents the results from experiments to investigate the temporal flux resolution and vertical mixed layer resolution necessary to accurately represent the diurnal variability of SST and its impact on intraseasonal time scales. Section 4 provides a summary and makes recommendations for the future configuration of coupled ocean-atmosphere models.

\section{Methodology}

\section{a. Defining and diagnosing diurnal and intraseasonal variability}

Here the vertical processes and flux variations that give rise to the observed diurnal and intraseasonal variations of the mixed layer are detailed. Specifically the nonlinearity of the upper-ocean response to the diurnal cycle and how this leads to diurnal variability of SST will be described. The modulation of the diurnal SST variability by the different flux regimes associated with the MJO is also discussed, and diagnostics for assessing model representation of diurnal and intraseasonal SST variability are introduced.

Before progressing, it is pertinent to clarify the meaning of some of the terms that will be used frequently in this paper, and which are often used with slightly different interpretations in the literature. First, the definition of the "mixed layer" and its depth are not consistent in the large body of work on the upper ocean. In this study, the mixed layer is defined as the depth at which the difference from the surface potential density is the same as would be caused by a change in temperature from the SST of $0.5^{\circ} \mathrm{C}$, in agreement with 
the work of Vialard and Delecluse (1998). This is often confused with what will here be referred to as the turbulent boundary layer, which is the depth to which surface-driven turbulent eddies can penetrate. This distinction is important to make as, though through mixing by eddies these two depths may often be very similar, they are often significantly different.

\section{1) DiURnal VARIABILITY}

The diurnal variability of SST seen during the IOP (Fig. 1) is a consequence of the contrasting vertical processes at work during daytime and nighttime. Windstress-induced turbulence; cooling via sensible, latent, and longwave radiative heat loss (combined as $Q_{\text {surf }}$ ); and salinity increases due to evaporation all act to destabilize the upper ocean. During the day this negative buoyancy flux is offset by the radiative forcing of the shortwave flux $\left(Q_{\mathrm{SWF}}\right)$, which is absorbed over the upper few tens of meters of the ocean.

The vertical gradient of the positive buoyancy forcing due to $Q_{\mathrm{SWF}}$ leads to the suppression of the vertical component of turbulent mixing caused by the destabilizing $Q_{\text {surf }}$ and wind stress. As a result of this suppression the turbulent boundary layer rapidly shoals, greatly reducing its heat capacity. Thus the temperature of the shoaling daytime boundary layer becomes increasingly sensitive to the heat fluxes that are causing it to shoal. This produces a daytime increase in mean mixed layer temperature and SST, while allowing an increase in buoyancy stratification to build up beneath the mixed layer due to the vertical gradient of absorption of $Q_{\mathrm{SWF}}$ and the associated buoyancy flux.

During the nighttime there is no suppression of turbulence by the absorption of $Q_{\mathrm{SWF}}$. Thus the mixed layer is dominated by the destabilizing $Q_{\text {surf }}$ and windinduced turbulence. As a result the nocturnal mixed layer deepens, "eroding" the buoyancy stratification that has built up beneath it during the day. As the mixed layer deepens, it redistributes the daytime heat gain over much greater depths, so the temperature of the mixed layer and SST drop accordingly.

It is this distinct nonlinearity between the ocean response to absorption of $Q_{\mathrm{SWF}}$ over depth and the negative surface buoyancy flux $Q_{\text {surf }}$ that causes the diurnal cycle of mixed layer depth and SST. These diurnal variations of SST may be as large as $2^{\circ} \mathrm{C}$ (Fig. 1), while the depth of the mixed layer may vary by as much as $50 \mathrm{~m}$.

\section{2) INTRASEASONAL VARIABILITY}

The observations from the IOP also exhibit intraseasonal variability in SST and in the magnitude of the diurnal SST variability (Fig. 1) in response to the different surface flux regimes of the active and suppressed phases of the MJO. The active phase is characterized by high winds and increased cloud cover. The reduced $Q_{\text {SwF }}$, coupled with the enhanced wind-driven turbu- lence and $Q_{\text {surf }}$, leads to a relatively deep mixed layer that cools slowly. During these periods the mixed layer does not shoal or warm significantly during the day. This is evident from the almost negligible diurnal signal of SST during the cooling phases marked "C" on Fig. 1.

By contrast, the suppressed phase of the MJO is associated with very high insolation, approaching $1000 \mathrm{~W}$ $\mathrm{m}^{-2}$, and very light winds. During these periods, when the diurnal variability is large, the very light winds mean that there is likely to be very little Langmuir circulation or surface wave breaking, so the absence of these processes throughout this study is unlikely to have a significant impact on the results. Under these conditions the relatively small wind-driven turbulence is easily suppressed by the strong vertical gradient of buoyancy forcing due to $Q_{\mathrm{SWF}}$. Thus the mixed layer is generally shallow with a net heat gain into the mixed layer and a gradual warming beneath due to the penetration of $Q_{\mathrm{SWF}}$. This absorption of $Q_{\mathrm{SWF}}$ beneath the mixed layer acts to moderate the cooling rate of the mixed layer in response to any subsequent deepening, as relatively warm water is then entrained. During warming phases (sections marked "W" in Fig. 1) the daytime mixed layer may shoal to as little as $1 \mathrm{~m}$, producing a very large diurnal signal in SST. Thus the different phases of the MJO lead to intraseasonal variations in SST and mixed layer temperature as well as a significant modulation of the magnitude of the diurnal variability of SST.

\section{3) Diagnostics}

To address the question of what temporal and vertical resolution is required to simulate the highfrequency behavior of the mixed layer, it is necessary to define appropriate measures of the diurnal and intraseasonal variability.

During the diurnal cycle the nocturnal minima in SST is essentially the "bulk" temperature of the mixed layer. Therefore, the evolution of SST in any modeling experiments that use daily mean fluxes can be expected to follow, to a very good approximation, the evolution of the nocturnal minima when using diurnally varying fluxes. Consequently, the diurnal cycle of SST will raise the daily mean SST above the bulk mixed layer temperature. As detailed in the previous section, the diurnal cycle is strongly modulated by the different phases of the MJO, being large in the warming phase (W in Fig. 1) and small in the cooling phase ( $\mathrm{C}$ in Fig. 1). This means that the increase of the daily mean SST by the diurnal cycle happens preferentially during the quiescent, warming phase of the $\mathrm{MJO}$, thereby increasing the magnitude of the intraseasonal variability. As the inclusion of the diurnal cycle will increase the intraseasonal variability toward more realistic values, we will refer to this enhancement of the intraseasonal variability by the diurnal cycle as the "rectification" of the intraseasonal variability by the diurnal cycle. 
There are consequently two quantities that we want to quantify in this study: namely, the magnitude of the diurnal variability of SST and the size of its rectification of the intraseasonal variability.

The magnitude of the diurnal cycle of on any particular day's SST is measured as the difference between the daytime maxima of SST and the mean of the preceding and subsequent nocturnal minima. The diurnal variability of SST will only significantly increase the daily mean, the effect of interest here, when it has a large amplitude. As a result, we will use a measure of the upper end of the magnitude distribution to quantify and compare the size of the diurnal variability of SST in the observations and each experiment. In this study, one standard deviation above the mean magnitude of the diurnal cycle of SST will be used to quantify the amplitude of the diurnal cycle. Other measures of the distribution of diurnal variability have been tested and have given good qualitative agreement.

Due to the relatively short sequence of observations from the IMET buoy, only three intraseasonal warming periods $\left(\mathrm{W}_{1}, \mathrm{~W}_{2}\right.$, and $\mathrm{W}_{3}$; Fig. 1) were observed, so the intraseasonal variability of SST cannot be as well defined as the diurnal variability. Consequently, the amplitude of the intraseasonal variability of SST is defined as the difference between the maximum SST during the warming period and the mean of the preceding and subsequent minima. This calculation is based upon the 3 -day running mean of the time series to avoid the influence of any freak days on the averaging.

\section{b. Model details and control configuration}

A 1D model incorporating the " $K$ "-profile parameterization (KPP) of Large et al. (1994) is used throughout this study. The KPP model uses a first-order turbulence closure scheme based upon similarity theory of turbulence in the boundary layer and includes nonlocal scalar transports throughout its depth. Shinoda and Hendon (1998) have shown the KPP model to be a useful tool for modeling the upper ocean during the IOP. Full details of the model and comparisons with other schemes are given in Large et al. (1994), where the KPP model is shown to perform at least as well as alternatives when forced by a number of surface flux regimes.

The version of KPP used in this study is identical to that presented by Large et al. (1994) with the exception that the convective velocity scale for scalers (their $C_{s}$ ) has been changed from 10 to $5 \mathrm{~m} \mathrm{~s}^{-1}$ following the work of Smyth et al. (2002).

A control integration representing the best possible simulation of the IMET observations is required against which to compare subsequent sensitivity experiments. An integration is performed on a grid of constant $25-\mathrm{cm}$ vertical resolution forced every $15 \mathrm{~min}$ (i.e., at every model time step) by data from the IMET observations using a quartic spline interpolation. This in- tegration was found to have only negligible differences (not shown) in comparison to an integration with 1-m vertical resolution and 1-h model time step and flux resolution. This null effect of increasing the vertical resolution and flux resolution while decreasing the model time step prompted the decision to configure the control (run CTL hereafter) as a constant 1-m resolution grid, forced by 1-h surface fluxes and using a 1-h model time step. In all subsequent integrations the model time step will be fixed at $1 \mathrm{~h}$.

The penetration of $Q_{\mathrm{SWF}}$ is modeling following Jerlov (1976), who showed that the transmission of shortwave radiation through seawater can be empirically modeled as a double exponential, with one wavelength band representing the absorption of the red half of the spectrum with an $e$-folding length of a few tens of centimeters and the other representing the absorption of the blue half of the spectrum over an $e$-folding length of a few tens of meters. Thus the irradiance $I$ at a depth $z$ can be written as

$$
I(z)=Q_{\mathrm{SWF}} \sum_{i=1}^{i=2} a_{i} e^{-z / b_{i}},
$$

where $a_{i}$ and $b_{i}$ are the coefficients of absorption and $i$ is the wavelength band index.

The values of wavelength band weightings and absorption coefficients are dependent upon the optical clarity of the water, or its "type." The model representation of diurnal variability was found to be sensitive to the prescribed water type due to the different vertical gradient of $Q_{\mathrm{SWF}}$ absorption and associated buoyancy flux. Smaller vertical gradients lead to a smaller build up of density stratification beneath the shallow daytime mixed layer. This allows the nocturnal mixing to penetrate to greater depths, redistributing the daytime heat gain over a greater depth and reducing the temperature of the mixed layer. It was found that, in accordance with Shinoda and Hendon (1998), water type IA gave the best representation of diurnal and intraseasonal SST variability with coefficient values of $a_{1}=0.62, b_{1}=$ $0.6, a_{2}=0.38$, and $b_{2}=20 \mathrm{~m}$.

The SST time series for run CTL is shown together with the observations in Fig. 1. A quantitative comparison of modeled and observed magnitude of the diurnal and intraseasonal variability of SST is given in Table 1. This shows that both diurnal and intraseasonal variabil-

TABLE 1. Summary of the diagnostics for selected integrations.

\begin{tabular}{lcc}
\hline \hline \multirow{2}{*}{ Integration } & \multicolumn{2}{c}{ Magnitude of SST variability $\left({ }^{\circ} \mathrm{C}\right)$} \\
\cline { 2 - 3 } & Diurnal & Intraseasonal \\
\hline Observations & 1.01 & 0.86 \\
CTL & 0.89 & 0.84 \\
12HR & 0.62 & 0.77 \\
12HR-offset & 0.07 & 0.57 \\
24HR & 0.01 & 0.50 \\
10M & 0.23 & 0.41 \\
\hline
\end{tabular}


o) Run CTL Temperoture

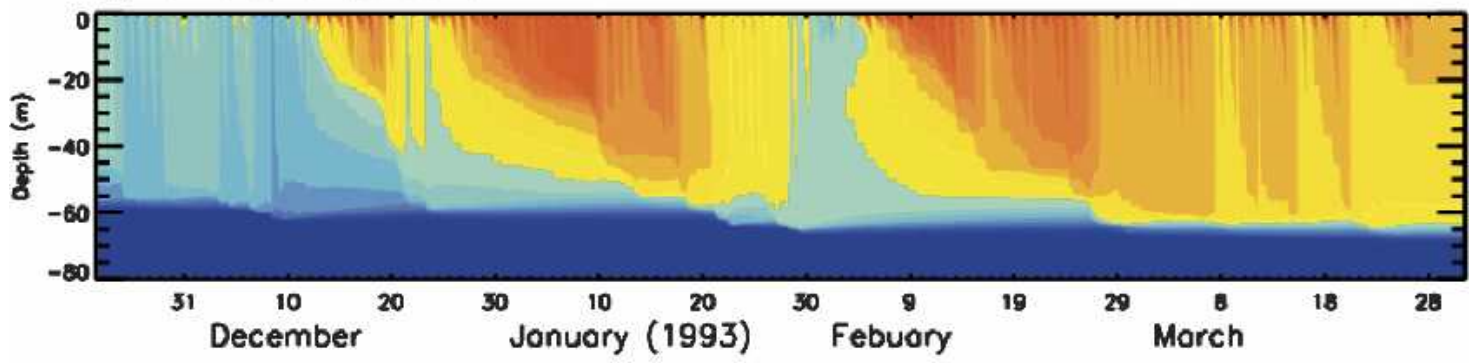

b) IMET Temperoture Observotions

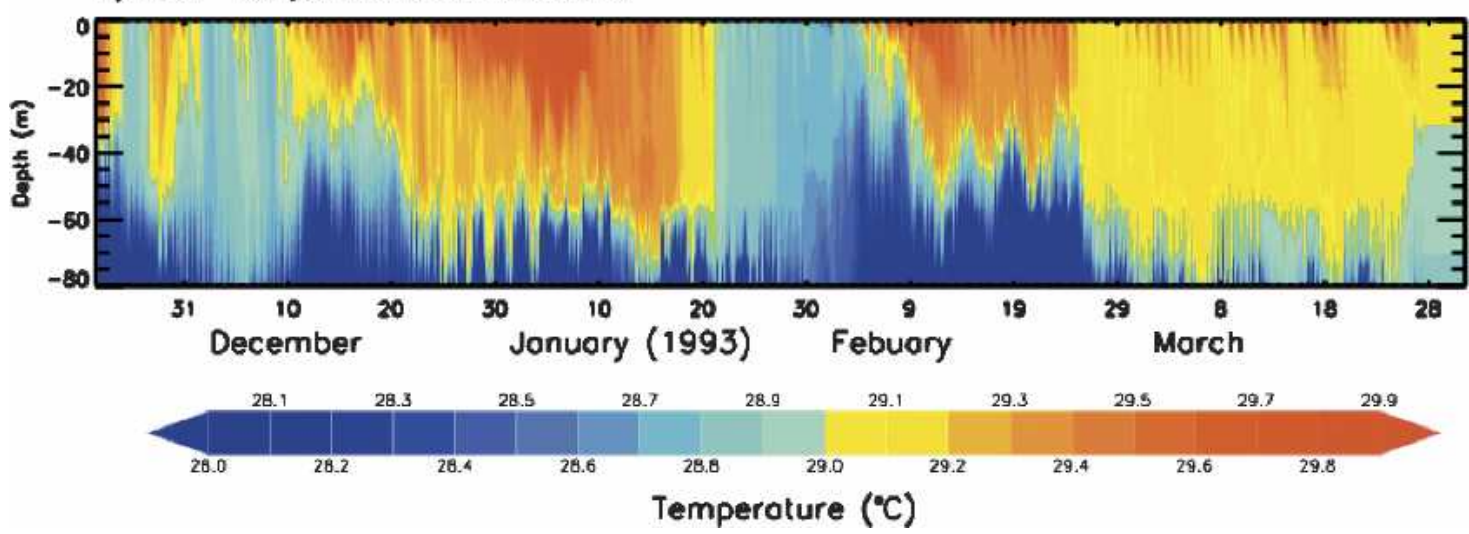

FIG. 2. Temperature profiles from (a) the control integration (run CTL) and (b) IMET observations. To aid comparison with the observations, the temperatures in CTL have been reduced uniformly by $0.5^{\circ} \mathrm{C}$ to remove the drift evident in Fig. 1.

ity of SST are well represented according to the previously defined diagnostics.

However, Fig. 1 shows that there is a noticeable displacement of SST between run CTL and the observations, due to a steady advection of heat out of the IFA, which has been documented in previous budget studies (Feng et al. 2000; Richards et al. 1995). This could in theory be corrected by the addition of an advective heat flux out of the model. However, the vertical profile of this advection is not clear. Applying a negative heat flux at the bottom of the mixed layer would lead to an increase in stability of the water column above, while applying an additional surface heat loss would have the opposite effect of destabilizing the water column. Both would affect the subsequent evolution of the upper ocean. Thus, in the absence of information on the profile of this advection, we chose to neglect it rather than risk applying an inappropriate additional heat flux.

\section{Results}

\section{a. Control integration}

Since Large et al. (1994) have already provided a detailed evaluation of the KPP model, only limited results will be presented in this paper. Figure 2 shows a time series of the temperature profiles from the IMET observations and run CTL. The model gives an excellent qualitative representation of the key features of the mixed layer evolution. The diurnal variability of the observations is well modeled over depth, as is the deepening of the mixed layer warming throughout the periods of intraseasonal warming. There are, however, a number of discrepancies evident between the time series of the observational temperature profile and that of run CTL. These include the absence of the semidiurnal tide or (up) downwelling at the depth of the thermocline (around $60 \mathrm{~m}$ ). These are manifestations of the $3 \mathrm{D}$ behavior of the ocean and the passage of internal waves, neither of which can be represented in a 1D model.

The rapid cooling of the mixed layer observed around 25 December 1992 is not well captured by the model. This is due to an underestimate of the strong entrainment from the thermocline in combination with a rare period of strong heat advection (Anderson et al. 1996; Feng et al. 2000) during a westerly wind burst. The modeling of entrainment directly from the thermocline is highly dependent upon vertical resolution and the relative position of grid points to the thermocline. This issue is not considered in the present study, but the main problems are outlined in Large et al. (1994). 
The final major difference between the observed and modeled temperature profiles is in the strength and timing of the near-surface cooling around 5 February (Fig. 2). This temperature inversion is related to a strong salinity anomaly (not shown), presumably resulting from a heavy rain event. However, the precipitation fluxes from the IMET data are the most poorly constrained of the meteorological surface fluxes, due to most of the measurements being taken at remote locations up to $2^{\circ}$ from the location of the IMET mooring. As already noted, the spatial heterogeneity of precipitation, errors in the measurements of precipitation, as well as the sparseness of subsurface salinity measurement make evaluation of the model salinity field difficult. Issues relating to the salinity variability of the mixed layer will be discussed in section 4 .

The excellent reproduction of the observations gives confidence in the applicability of the 1D approach used here and in the performance of the model. Run CTL will now be considered as a "perfect" model of the mixed layer for the rest of this study, with the aforementioned discrepancies ascribed to the $3 \mathrm{D}$ behavior of the ocean.

\section{b. Flux resolution}

\section{1) Daily MEAN FluXes}

To quantify the aspects of the diurnal cycle of the upper ocean that may be important for the longer-term evolution of the tropical climate, a comparison is made between run CTL and an integration forced with daily mean fluxes from the IOP (run 24HR) where heat fluxes are constant at the daily mean value for each local day, as opposed to each day in UTC or a running 24-h mean. Run $24 \mathrm{HR}$ is representative of the flux resolution of most state-of-the-art ocean-atmosphere climate models.

A representative sample of the model turbulent boundary layer depth and SST from runs CTL and 24HR is shown in Fig. 3, with the results of the previously defined diagnostics of diurnal and intraseasonal variability for these runs presented in Table 1. Both integrations display intraseasonal variability associated with the passage of the MJO during the IOP. However, the absence of the diurnal cycle of fluxes in run 24HR results in a significant underestimate of the intraseasonal variability of daily mean SST, indicating that the diurnal cycle is clearly rectifying the intraseasonal time scales. As a result, the magnitude of intraseasonal variability of run $24 \mathrm{HR}$ is $0.34^{\circ} \mathrm{C}$ smaller than in run CTL (Table 1). This is a $40 \%$ underestimate and represents a significant reduction in the sensitivity of the SST to the different flux regimes associated with the MJO. It implies a reduced sensitivity of the ocean to the atmosphere in climate models that use daily coupling, consistent with the findings of Inness and Slingo (2003).

As well as its rectification of the intraseasonal variability of SST, there is a suggestion from these runs that a) Sea surface temperature
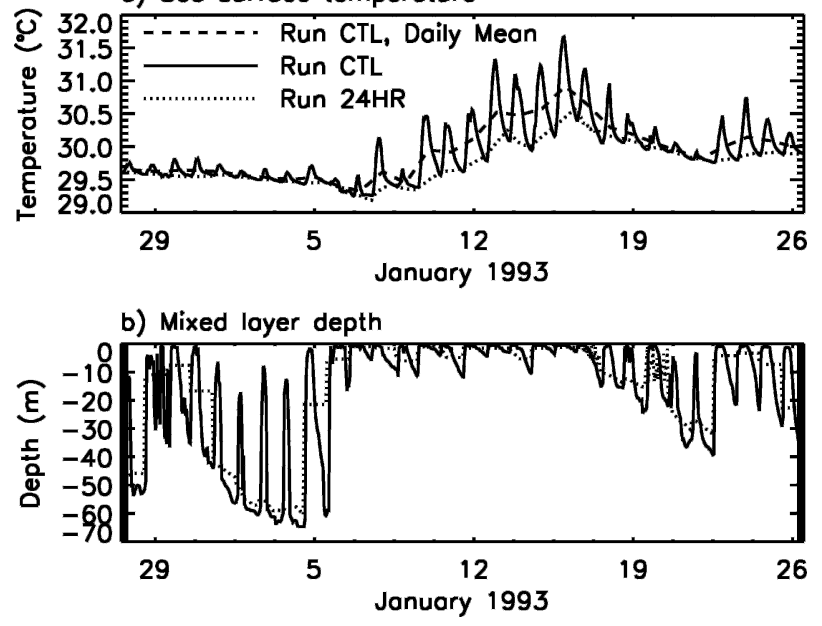

FIG. 3. (a) Sample SST and (b) turbulent boundary layer depth time series from the control integration (run CTL; solid line) with 1-hourly fluxes and the sensitivity experiment with daily mean fluxes (24HR; dotted line). The dashed line shows the daily mean SST from the control integration to emphasize the intraseasonal variability.

the diurnal cycle is also important in the interaction of the mixed layer with the deeper ocean below. Whereas the absence of the shallow daytime mixed layer during the suppressed phase of the MJO leads to errors in the SST in the case of 24HR, without strong nocturnal convection the mixed layer is systematically too shallow during the night (Fig. 3b). During the active phase of the MJO, when the nocturnal mixed layer is deep, the exchange of properties with the deeper ocean by entrainment at the base of the mixed layer is reduced in run 24HR. As a result, the positive net surface fluxes of heat and freshwater, typical of the warm pool, are mixed less with the cooler more saline water beneath the mixed layer. This is especially evident in the comparison between the daily mean profiles from the end of the IOP (Fig. 4) showing the accumulated effect of the reduced mixing at the base of the mixed layer. The surface fluxes of heat and freshwater have been trapped in the upper layers, leading to an increase in the buoyancy stratification at the base of the mixed layer, which then further suppresses entrainment. This positive feedback acts to "decouple" the mixed layer from the ocean beneath, leading to a steady drift of run 24HR toward warmer and fresher mixed layer conditions and to a 5-m difference in the depth of the thermocline after the 4-month IOP. If this drift is then extrapolated to longer time scales, it suggests a gradual warming of the order of $0.4^{\circ} \mathrm{C} \mathrm{yr}^{-1}$, a very significant rate on climate time scales.

These comparisons show that the diurnal cycle is potentially an important process, not only in the coupling of the atmosphere and ocean on intraseasonal time scales, but possibly also in determining the mean state 


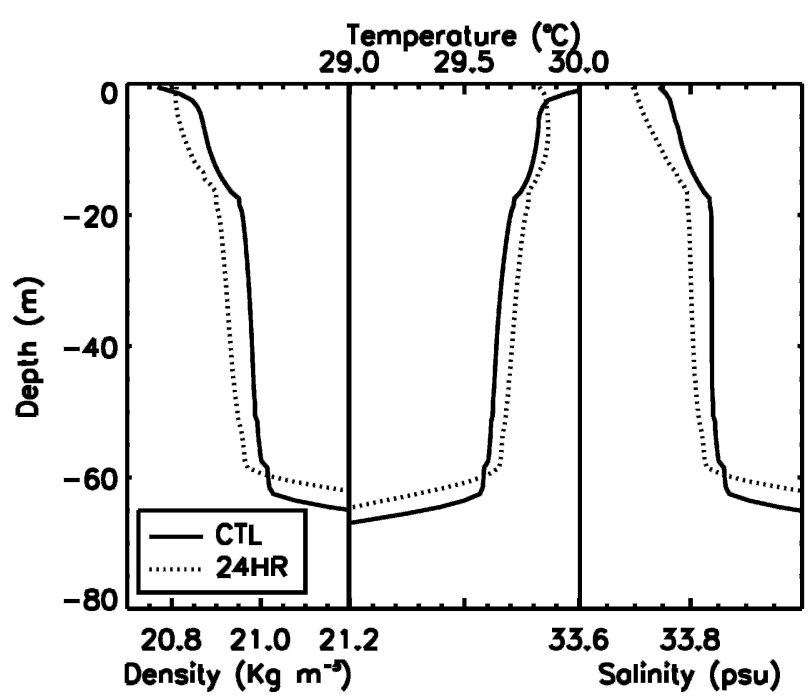

FIG. 4. Daily mean density, temperature, and salinity profiles from the end of runs CTL (solid) and 24HR (dotted).

of the mixed layer via its influence on the interaction between the upper ocean and the deeper ocean.

\section{2) The SEnSitivity of THE DIURNAL CYCLE to THE FREQUENCY OF COUPLING}

The simplest way to include the diurnal cycle would be to use two phases representing the day and the night, each of constant flux and lasting $12 \mathrm{~h}$. The results from an integration forced at such a flux resolution (run 12HR) are shown in Fig. 5. There is a very pronounced diurnal variation of SST and turbulent boundary layer depth apparent. The magnitude of the diurnal cycle is $0.62^{\circ} \mathrm{C}$ in run $12 \mathrm{HR}$ compared to $0.89^{\circ} \mathrm{C}$ in run CTL.

a) Sea surfoce temperature
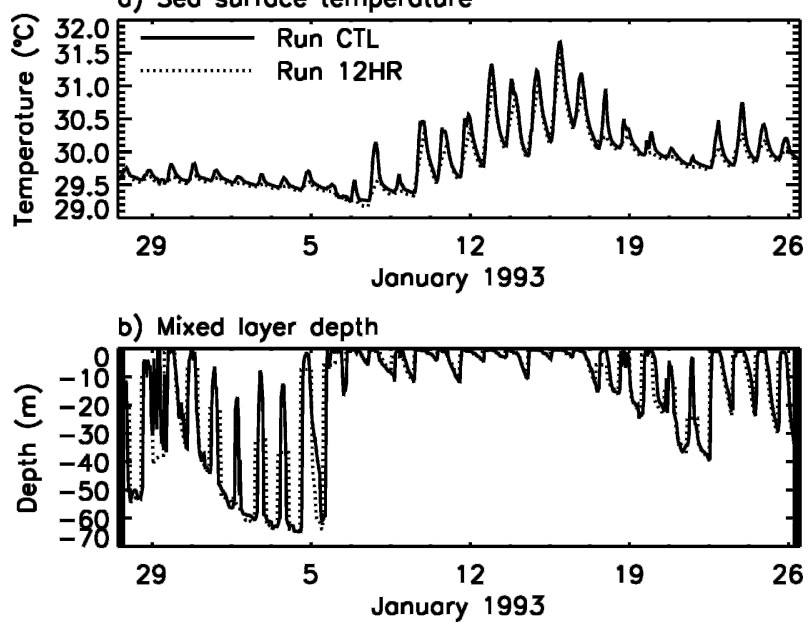

FIG. 5. (a) Sample SST and (b) turbulent boundary layer depth time series from the control integration (run CTL; solid line) with 1-hourly fluxes and the sensitivity experiment with 12-hourly fluxes centered on midday/midnight (12HR; dotted line).
This enhances the intraseasonal variability of the daily mean SST to $0.77^{\circ} \mathrm{C}, 92 \%$ of the amplitude in run CTL. The remaining underestimate of the diurnal cycle of SST in run $12 \mathrm{HR}$ is due to the daily maximum $Q_{\mathrm{SwF}}$ being underestimated by the averaging, leading to a less pronounced shoaling of the mixed layer and associated warming.

On the other hand, the slowly varying nature of the nocturnal surface fluxes means that they are well resolved at a temporal resolution of $12 \mathrm{~h}$ (Figs. 6a, b). Although the results shown in Fig. 5 suggest that 12hourly coupling can capture most of the diurnal and intraseasonal variability, the design of coupled general circulation models (CGCMs) precludes such a solution. CGCM components are coupled at the same instant over a global domain, which means that the local time of coupling varies depending upon longitude. As a re-

a) Typical surface heat fluxes

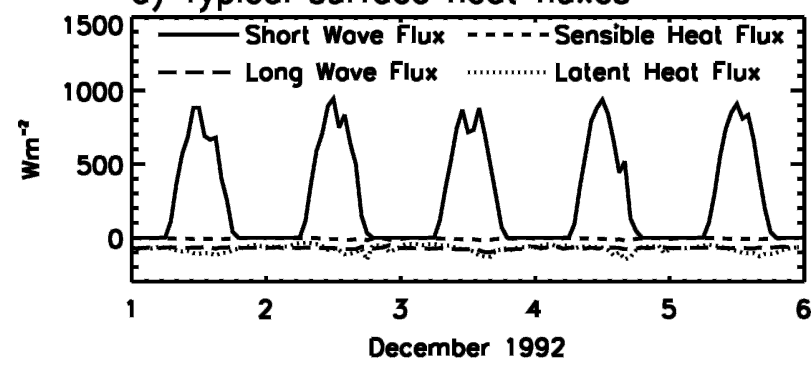

b) Typical total heot fluxes

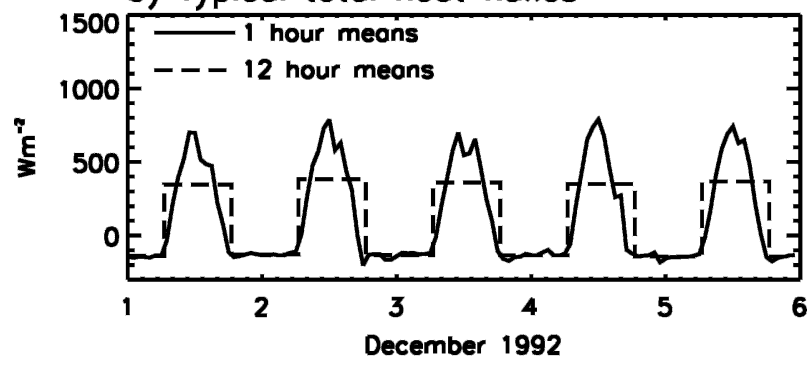

c) Typical total heat fluxes

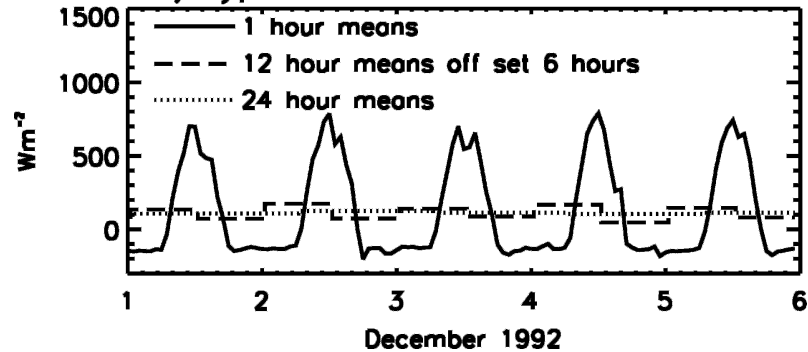

FIG. 6. Effect of averaging period and local time of averaging on surface fluxes as given by the 1-hourly IMET observations. (a) Typical surface fluxes from the suppressed phase of the MJO; (b) 12 -hourly average net surface fluxes when the averaging period is centered on midday and midnight. Note that the nocturnal fluxes are well captured. (c) Same as in (b) but for an averaging period centered on dawn and dusk [i.e., offset by $6 \mathrm{~h}$ from (b)]. Note the almost complete absence of the diurnal cycle. 


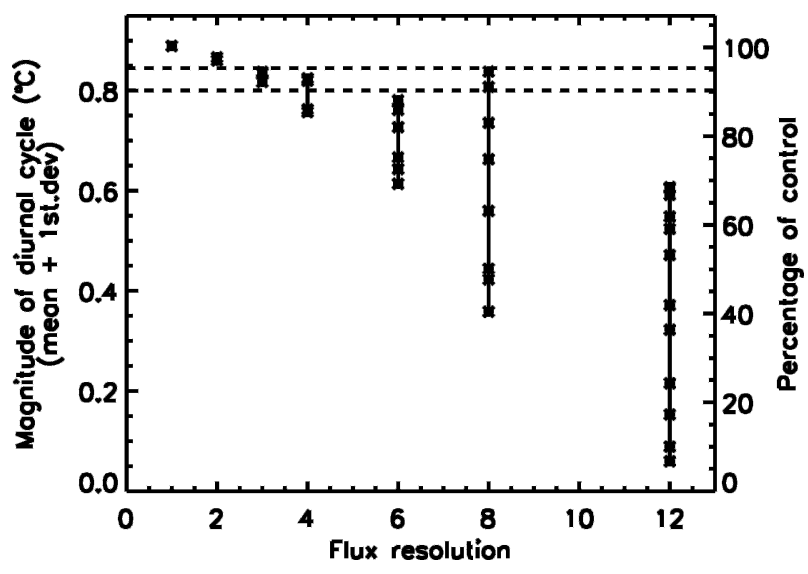

FIG. 7. Magnitude of diurnal cycle for all possible offsets of averaging period from local midday. Offset of the centering of the averaging period represents different longitudes when considering a global domain. The crosses show the values for different offsets, and the solid lines represent the range of possible results for different flux resolutions. The values of $90 \%$ and $95 \%$ of run CTL are indicated by dashed lines.

sult, the 12-h averaging period of fluxes would mean that fluxes were centered around different local times of day. Although a given location could be chosen so as to center the flux averaging around midday/midnight and give fluxes, such as those in Fig. $6 \mathrm{~b}$, at $90^{\circ}$ east or west, the flux averaging period would be $6 \mathrm{~h}$ ahead or behind midday/midnight. The resultant averaged fluxes (Fig. 6c) essentially reproduce the daily mean fluxes with minimal diurnal cycle. An integration with 12 -h fluxes offset by $6 \mathrm{~h}$ is performed (run 12HR-offset), and the results are summarized in Table 1 . The implication of this is that a 12-h coupling frequency would induce a strong geographical bias in the representation of the diurnal cycle.

To assess this geographical bias, the results at a given flux resolution must be considered for all possible offsets or local time of day for the flux averaging period. As such, the worst possible case needs to be considered as well as the entire range of results. A number of subsequent integrations are performed at different flux resolutions for all possible offsets, that is, local times for the flux averaging period. Flux resolutions used were chosen to be integer divisions of $24 \mathrm{~h}$ so as to avoid aliasing the diurnal signal onto longer time periods and unduly biasing the results. The SST variability diagnostics are performed on the integrations, and the results are shown in Figs. 7 and 8.

It is evident from Fig. 7 that, if the local time of day of the flux averaging period could be specified exactly, then $90 \%$ of the diurnal variability of SST would be captured using a 6-h flux resolution. On the other hand, in the current design of CGCMs, a coupling frequency of $3 \mathrm{~h}$ would be necessary for the same level of representation of the diurnal variability of SST globally. Figure 8 shows the effect of the rectification of the in-

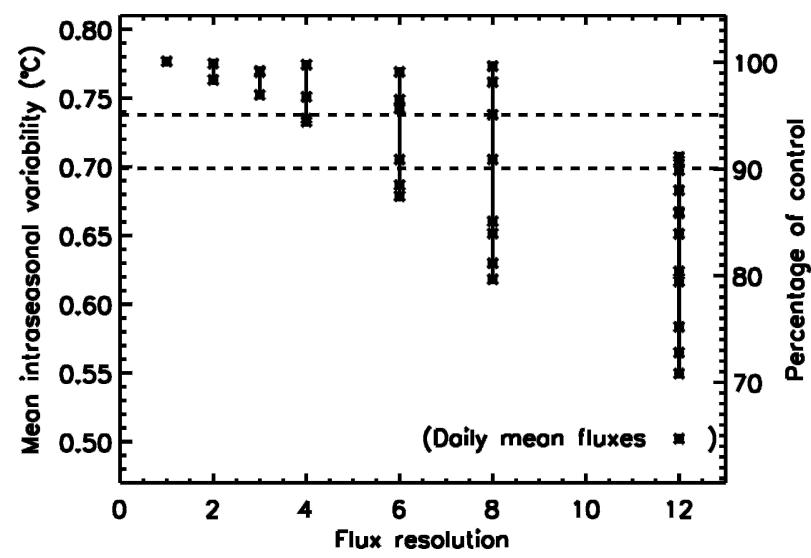

FIG. 8. Same as in Fig. 7 but for the magnitude of intraseasonal variability

traseasonal variability by the diurnal cycle of SST. If the optimal local time of day of the flux averaging period can be specified, then $95 \%$ of the intraseasonal variability can be represented with a 6-h flux resolution. However, if this level of accuracy is required over a global domain, then a coupling frequency of $3 \mathrm{~h}$ would be required in present CGCMs to avoid any geographical bias.

Figures 7 and 8 both show counterintuitive results for the case of 8-h flux resolution. Diurnal and intraseasonal variability of SST can be better represented by an 8-hourly flux resolution than 6-hourly in some locations; however, the inability of an 8-h flux resolution to resolve properly both a 12 -h night and a 12 -h day simultaneously leads to considerable errors in nocturnal entrainment, with a large geographical bias.

\section{c. Vertical resolution}

In assessing the necessary vertical resolution to model the diurnal variability of SST, an initial integration forced with 1-hourly fluxes on a grid of constant 10-m resolution (run 10M) was performed. This is representative of the typical resolution of the upper ocean in state-of-the-art ocean and coupled models. Figure 9 shows that such a configuration is unable to resolve the diurnal variability of SST and hence intraseasonal variability, the magnitudes of the diurnal and intraseasonal SST variability being $0.23^{\circ}$ and $0.41^{\circ} \mathrm{C}$, respectively (see Table 1).

The sensitivity of the modeled diurnal SST variability to vertical resolution is shown in Fig. 10. There is strong dependence of the magnitude of the diurnal cycle of SST on the vertical resolution, with the magnitude increasing rapidly with improved vertical resolution. However, as the resolution of the model is further increased beyond $1 \mathrm{~m}$, the magnitude of the diurnal cycle of the SST does not increase further. This sensitivity in Fig. 10 can be explained by the representation of the absorption of shortwave radiation $\left(Q_{\mathrm{SWF}}\right)$. The red half 
a) Sea surfoce temperature

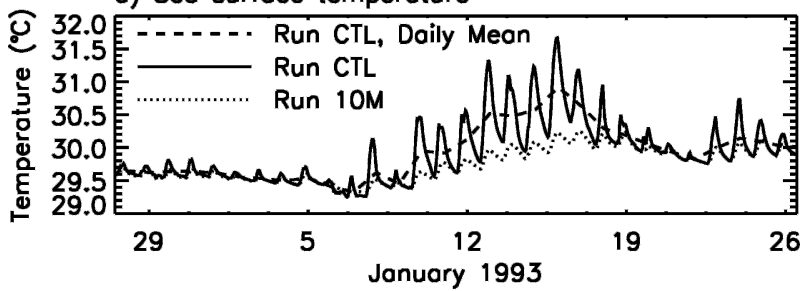

b) Mixed loyer depth

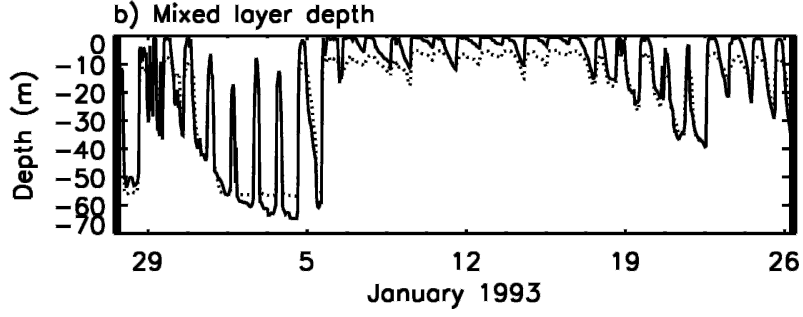

FIG. 9. (a) Sample SST and (b) turbulent boundary layer depth time series from the control integration (run CTL; solid line) with 1-hourly fluxes and the sensitivity experiment with 10 -m vertical resolution (10M; dotted line).

of the spectrum is absorbed almost entirely in the upper $1 \mathrm{~m}$ of the model and so, in the absence of any mixing, a model level this thick will heat rapidly during the day. In comparison, although a 10-m-thick uppermost layer would be subject to a $10 \%$ larger net heat flux, the heat capacity would be increased by an order of magnitude leading to a much slower increase in temperature. As the model SST is the temperature of the uppermost level, the rate of change of model SST, in the absence of mixing, can be written as

$$
\frac{d \mathrm{SST}}{d t}=\frac{1}{\rho C_{p} \Delta h}\left[Q_{\mathrm{surf}}+Q_{\mathrm{SWF}}\left(1-\sum_{i=1}^{i=2} a_{i} e^{-\Delta h / b_{i}}\right)\right],
$$

where $Q_{\text {surf }}$ is the combined surface heat losses of longwave radiation and latent and sensible heat fluxes, $\rho$ the density, $C_{p}$ the specific heat, $a_{i}$ and $b_{i}$ are the coeffi-

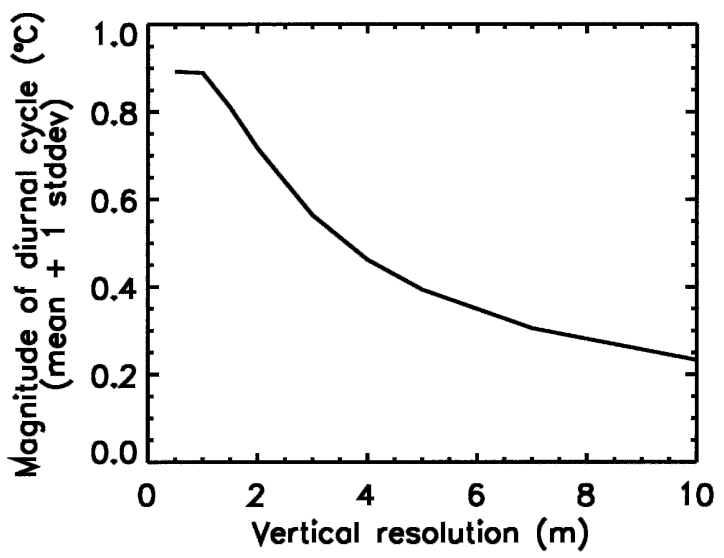

FIG. 10. The diagnosed magnitude of the diurnal variability SST for configurations of different linear resolutions. cients of absorption that are dependent upon the water clarity, $i$ is the wavelength band index, and $\Delta h$ the uppermost level thickness. The solid line in Fig. 11 shows this function for typical daytime values of $Q_{\text {surf }}$ and $Q_{\mathrm{SWF}}$ of -200 and $800 \mathrm{~W} \mathrm{~m}^{-2}$, respectively. The rate of increase of SST is strongly dependent on the thickness of the uppermost layer, with maximum values occurring for an upper level thickness of the order of $1 \mathrm{~m}$. The thickness of the upper level for which the maximum in $d \mathrm{SST} / d t$ occurs varies by about $20 \%$ for a range of reasonable choices of $Q_{\text {surf }}$ and $Q_{\mathrm{SWF}}$.

The dashed line in Fig. 11 shows the difference between the heating rate of the uppermost level and the level below. If the model resolution is such that the upper layer thickness is reduced to about $50 \mathrm{~cm}$, the strong surface cooling will dominate over the shortwave heating in the upper layer and the surface level will cool relative to the level below. Such a situation will give rise to convective instability, and the mixing will homogenize the upper levels to a depth such that the heating in the mixed layer is greater than or equal to that below. In fact, in almost all cases there will be sufficient generation of turbulence, either by the wind or surface waves (which are not included in this model), to overcome a weakly stabilizing forcing; hence the mixed layer will always be slightly deeper than would be predicted by considering the level at which the upper layer warms at a greater rate than the level below.

For very high vertical resolutions the magnitude of the diurnal cycle of SST is no longer limited by the vertical resolution but by the minimum depth to which the mixed layer can shoal. For these experiments with the KPP model, it appears that this limit is of the order of $1 \mathrm{~m}$ and, providing that the vertical grid can resolve this depth of mixed layer, increasing the vertical resolution will not increase the magnitude of the diurnal cycle.

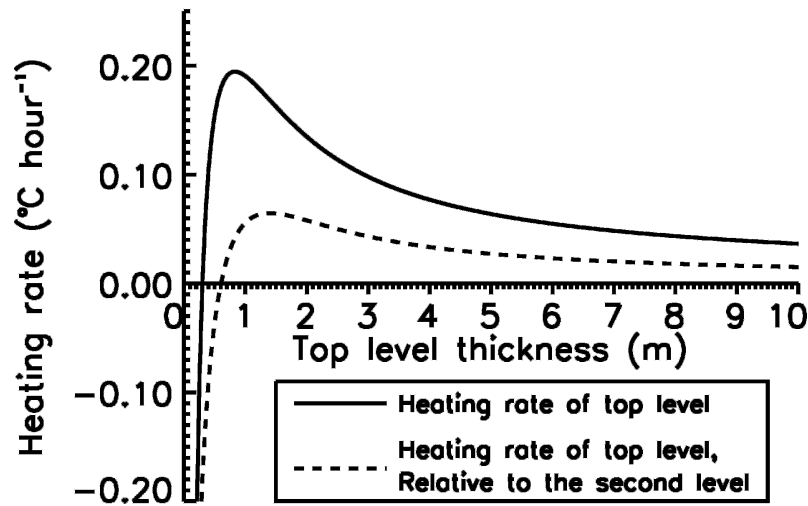

FIG. 11. The dependence of heating rate of the uppermost model level due to surface fluxes as a function of the layer thickness (solid line) and the relative heating rate of the uppermost level relative to the second model level (dashed). The calculation assumes that the surface cooling is fixed at $-200 \mathrm{~W} \mathrm{~m}^{-2}$ and the shortwave flux is $800 \mathrm{~W} \mathrm{~m}^{-2}$. 


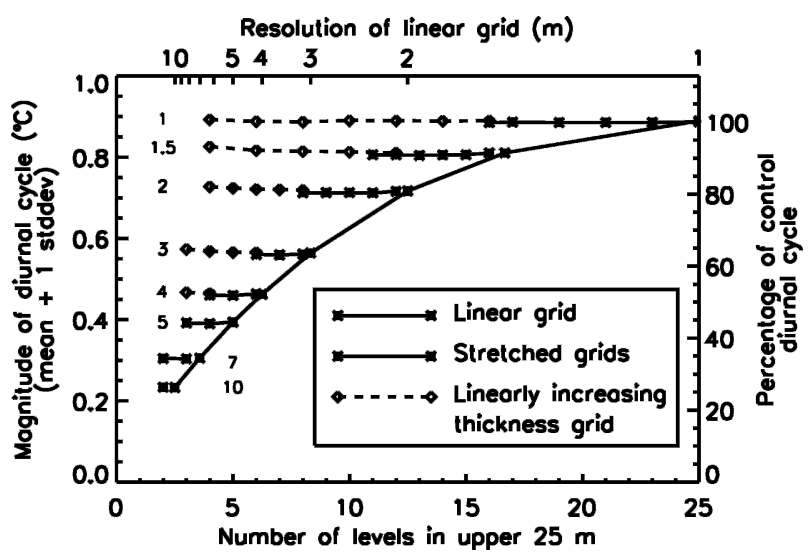

FIG. 12. Magnitude of the diurnal SST variability for a series of linear, stretched, and linearly increasing grids. The fixed upperlayer thickness of each series of grids is marked on the figure.

Whether this model properly represents these processes in light wind conditions or whether conditions can occur that would allow a shallower mixed layer to form is beyond the scope of this study, not least because the IMET data have no better than $0.5-\mathrm{m}$ resolution in the upper few meters of the ocean. For this model and these forcing conditions the modeled magnitude of the diurnal cycle of SST cannot be increased by increasing the resolution beyond $1 \mathrm{~m}$.

To quantify the significance of the upper-layer thickness in linear grids of constant thickness, comparisons are made against integrations on exponentially stretched grids (as described in the appendix of Large et al. (1994)) of fixed upper level thickness but varying resolution beneath. In addition to the stretched grids, configurations with linearly increasing level thickness are constructed to enable the resolution of the upper level to remain fixed while reducing the resolution beneath by more than is possible with the stretched grids. A proxy for the resolution below the uppermost level used here is the number of grid levels in the upper $25 \mathrm{~m}$. This is chosen because during the suppressed phase of the MJO, when the diurnal SST signal is most pronounced, the turbulent boundary layer depth never deepens to more than $25 \mathrm{~m}$ (Fig. 3b).

The diurnal SST variability of these integrations is shown in Fig. 12, where the numbers in the body of the figure refer to the thickness of the uppermost layer of the adjacent line of points. The results demonstrate that, keeping the thickness of the uppermost level constant while reducing the resolution beneath, has no effect upon the magnitude of the modeled diurnal SST variability. The implication is that, regardless of the resolution of the upper ocean (and of the flux resolution) if the uppermost level is not sufficiently thin, then a model will not accurately resolve the diurnal variations of SST or its rectification of intraseasonal timescale variability. This rectification is demonstrated in Fig. 13. Apart from the very lowest mixed layer reso-

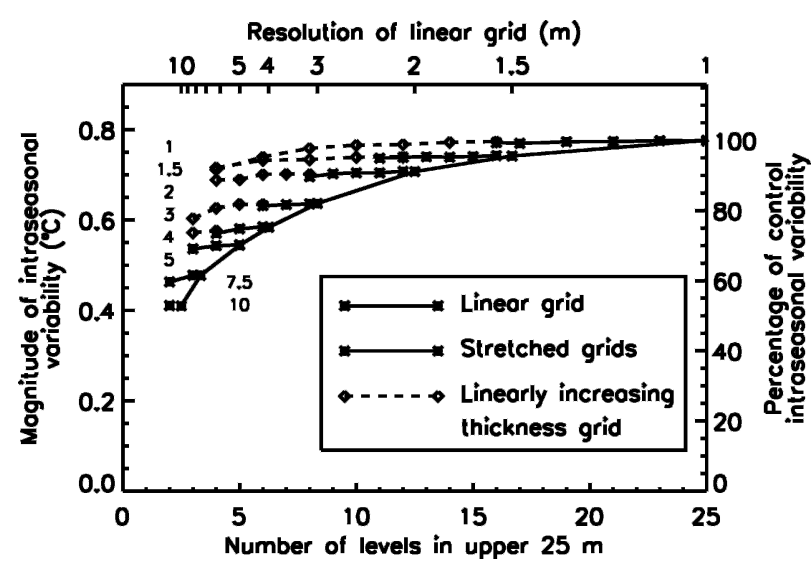

FIG. 13. Same as in Fig. 12 but for intraseasonal variability of SST.

lution integrations, the magnitude of the intraseasonal variations are primarily governed by the model's ability to resolve the diurnal cycle of SST. It does, however, show that a certain degree of resolution is still required to resolve the underlying intraseasonal variability, though this has not been robustly quantified.

\section{Conclusions}

It has been shown that the diurnal cycle of SST greatly increases the intraseasonal variability of daily mean SST. Its absence in the KPP model has been shown to result in an underestimation of intraseasonal SST variability of $0.34^{\circ} \mathrm{C}$, associated with the passage of the MJO. This constitutes a $40 \%$ reduction in the sensitivity of SST to the intraseasonal variability of atmospheric forcing.

High vertical resolution model integrations have shown that $90 \%$ of the diurnal variability of SST can be reproduced using a 6-h flux resolution, provided that the local time of day of the flux averaging period can be optimally specified. Due to the design of CGCM this is not possible on a global domain owing to the change in local time with longitude. Thus to capture at least $90 \%$ of the diurnal variability of SST, without significant geographical bias in its representation, the coupling frequency of CGCM must be reduced to $3 \mathrm{~h}$ or less.

There is also suggestion from the results of this study that the diurnal cycle may be important for the interaction between the upper ocean and the deeper ocean. The western Pacific is a region of net positive heat and freshwater fluxes. Poor representation of the strong nocturnal convection and the accompanying entrainment causes an accumulation of warm, fresh, buoyant water in the mixed layer. This increases the density stratification between the mixed layer and the deeper ocean beneath, further inhibiting entrainment. This positive feedback may act to decouple the mixed layer from the rest of the ocean, effect the evolution of the 
upper thermocline, and causes a drift in the mixed layer salinity and temperature. It was found that the associated drift in mean mixed layer temperature was of the order of $0.1^{\circ} \mathrm{C}$ over the 4-month integrations, and we suggest that the diurnal cycle may also contribute to the mean state of the upper ocean in the tropical warm pool through this process, though caution must be used in interpreting the significance of this extrapolated drift in such a simple model with no dynamics or atmospheric feedbacks. However, this hypothesis is currently being addressed in full 3D OGCM simulations.

The simulation of diurnal SST variability is found to depend crucially upon the resolution of the uppermost model level. To capture the maximum heating rates of the diurnal cycle, the uppermost level must be of the order of $1 \mathrm{~m}$ thick due to the nature of the vertical profile of absorption of shortwave radiation. Ocean models with 10-m-thick upper levels are unable to capture the observed magnitude of diurnal SST variability or its rectification of intraseasonal times scales in the tropical warm pools.

It is acknowledged that the optimum configuration of an ocean model to capture the diurnal cycle, presented here as 1-m vertical resolution and hourly fluxes, may be an unrealistically costly proposition for current CGCMs. Figure 14 gives an indication of the relative merits of improvements in coupling frequency and vertical resolution. The values for coupling frequency shown in Fig. 14 are taken from the worst possible offset of flux averaging period for a given flux resolution and thus represent the lower bound of what may be achieved. The vertical resolution is that of the uppermost level, as the insensitivity to resolution below the upper level has been demonstrated for the KPP model and is likely to hold for other mixing schemes. It is proposed that Fig. 14 be used as the basis of a cost function for the improvements to CGCMs needed to resolve the diurnal cycle in the upper ocean and its effects upon the tropical climate.

This study has focused on the role of the diurnal cycle in the upper ocean and as such has considered the temperature variability of the mixed layer due to its strong diurnal signal. No attention has been paid to the effects of salinity due to the sparseness of subsurface IMET salinity data and inaccuracies in the precipitation data. It is recognized, however, that the fine vertical salinity structure observed in the western Pacific (Lukas and Lindstrom 1991; Weller and Anderson 1996) is undoubtedly important for the evolution and variability of the mixed layer through, for example, the presence of salinity-stratified barrier layers (Vialard and Delecluse 1998). The spatial heterogeneity of precipitation and the role of advection in such processes (Lukas and Lindstrom 1991; Dourado and Caniaux 2003) mean that the present $1 \mathrm{D}$ vertical model is an inappropriate tool for the study of salinity in the mixed layer in the warm pool. The results of such an investigation would most likely impose greater requirements on the vertical

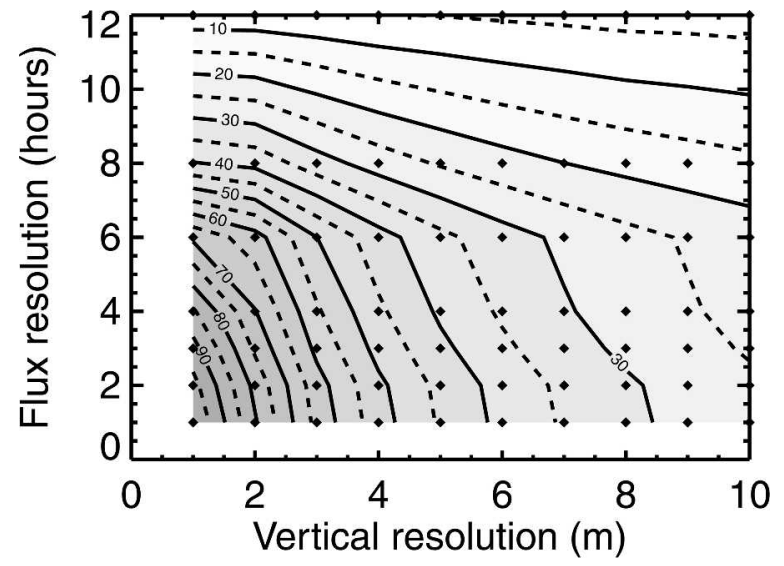

FIG. 14. Phase diagram showing the diurnal SST variability as a function of flux resolution and vertical resolution of the uppermost model level. Contours show the percentage of the magnitude of the diurnal variability in the control integration CTL. For the flux resolution, the results from the least optimal averaging period are used, that is, the lower limits of the bars shown in Fig. 7.

resolution throughout the mixed layer, rather than just that of the uppermost layer as suggested by this study. Future work will focus upon the role of ocean salinity in the variability of the tropical climate system by using a high vertical resolution ocean component in a CGCM with an explicitly resolved diurnal cycle.

Acknowledgments. D. Bernie and S. Woolnough acknowledge NERC's support through grant NER/A/S/ 2000/1283. J. Slingo is a member of the NERC Centres for Atmospheric Science (NCAS). E. Guilyardi also acknowledges the support of IPSL/CNRS for this research. We thank Bill Large for the provision of and advice on the KPP mixed layer code. Helpful discussions with Gurvan Madec (IPSL) are acknowledged. The authors would also like to thank the two anonymous reviewers for their comments, which helped to significantly improve the quality and clarity of the manuscript.

\section{REFERENCES}

Anderson, S. P., R. A. Weller, and R. B. Lukas, 1996: Surface buoyancy forcing and the mixed layer of the western Pacific warm pool: Observations and 1D model results. J. Climate, 9, 3056-3085

Dourado, M., and G. Caniaux, 2003: Surface salinity budget in oceanic simulation using data from TOGA COARE. J. Geophys. Res., 108, 3135, doi:10.1029/2001JC001013.

Cronin, M. F., and M. J. McPhaden, 1998: Upper ocean salinity balance in the western equatorial Pacific. J. Geophys. Res., 103, 27 567-27 587.

Feng, M., R. Lukas, P. Hacker, R. Weller, and S. Anderson, 2000: Upper-ocean heat and salt balances in the western equatorial Pacific in response to the intraseasonal oscillation during TOGA COARE. J. Climate, 13, 2409-2427.

Flatau, M., P. J. Flatau, P. Phoebus, and P. P. Niiler, 1997: The feedback between equatorial convection and local radiative 
and evaporative processes: The implications for intraseasonal oscillations. J. Atmos. Sci., 54, 2374-2385.

Hendon, H. H., 2000: Impact of air-sea coupling on the MaddenJulian oscillation in a general circulation model. J. Atmos. Sci., 57, 3939-3951.

— tropical Indian and Pacific Oceans. J. Climate, 10, 647-661.

Inness, P. M., and J. M. Slingo, 2003: Simulation of the MaddenJulian oscillation in a coupled general circulation model. Part I: Comparison with observations and an atmosphere-only GCM. J. Climate, 16, 345-364.

, - E. Guilyardi, and J. Cole, 2003: Simulation of the Madden-Julian oscillation in a coupled general circulation model. Part II: The role of the basic state. J. Climate, 16, 365-384.

Jerlov, N. G., 1976: Marine Optics. Elsevier, 231 pp.

Johnson, R. H., T. M. Rickenbach, S. A. Rutledge, P. E. Ciesielski, and W. H. Schubert, 1999: Trimodal characteristics of tropical convection. J. Climate, 12, 2397-2418.

Large, W., J. McWilliams, and S. Doney, 1994: Oceanic vertical mixing: A review and a model with a nonlocal boundary layer parameterization. Rev. Geophys., 32, 363-403.

Lukas, R., and E. Lindstrom, 1991: The mixed layer of the western equatorial Pacific Ocean. J. Geophys. Res., 96 (Suppl.), 3343 3357.

Richards, K. J., and M. E. Inall, 2000: The upper ocean heat content of the western equatorial Pacific: Processes controlling its change during the Tropical Ocean-Global Atmosphere Coupled Ocean-Atmosphere Response Experiment. J. Geophys. Res., 105, 19 575-19590.

_,- , and N. C. Wells, 1995: The diurnal mixed layer and the upper ocean heat budget in the western equatorial Pacific. $J$. Geophys. Res., 100, 6865-6879.

Shinoda, T., and H. H. Hendon, 1998: Mixed layer modeling of intraseasonal variability in the tropical western Pacific and Indian oceans. J. Climate, 11, 2668-2685.

,$- \ldots$, and J. Glick, 1998: Intraseasonal variability of surface fluxes and sea surface temperatures in the tropical western Pacific and Indian Oceans. J. Climate, 11, 1685-1702.

Slingo, J. M., and Coauthors, 1996: Intraseasonal oscillations in 15 atmospheric general circulation models: Results from an AMIP diagnostics subproject. Climate Dyn., 12, 325-357.

Smyth, W. D., E. D. Skyllingstad, G. B. Crawford, and W. Hemantha, 2002: Nonlocal fluxes and Stokes drift effects in the K-profile parameterization. Ocean Dyn., 52, 104-115.

Vialard, J., and P. Delecluse, 1998: An OGCM study for the TOGA decade. Part I: Role of salinity in the physics of the western equatorial fresh pool. J. Phys. Oceanogr., 28, 10711088.

Waliser, D. E., K. M. Lau, and J.-H. Kim, 1999: The influence of coupled sea surface temperatures on the Madden-Julian oscillation: A model perturbation experiment. J. Atmos. Sci., 56, 333-357.

Wang, B., and X. Xie, 1998: Coupled modes of the warm pool climate system. Part I: The role of air-sea interaction in maintaining the Madden-Julian oscillation. J. Climate, 11, 2116 2135 .

Weller, R., and S. Anderson, 1996: Surface meteorology and airsea fluxes in the western equatorial Pacific warm pool during the TOGA Coupled Ocean-Atmosphere Response Experiment. J. Climate, 9, 1959-1991.

Woolnough, S. J., J. M. Slingo, and B. J. Hoskins, 2000: The relationship between convection and sea surface temperature on intraseasonal timescales. J. Climate, 13, 2086-2104.

- _ _ and _ 2001: The organization of tropical convection by intrasesonal sea surface temperature anomalies. Quart. J. Roy. Meteor. Soc., 127, 887-907. 